REVIEW

\title{
Acute on chronic liver failure: From pathophysiology to clinical management
}

\author{
Francesco Vizzutti, Umberto Arena, Giacomo Laffi, Fabio Marra* \\ Dipartimento di Medicina Sperimentale e Clinica, University of Florence, Italy
}

\section{Keywords:}

Cirrhosis

Hepatic encephalopathy

Sepsis

Portal hypertension

Hepatorenal syndrome

\begin{abstract}
S U M M A R Y
Acute on chronic liver failure (ACLF) is currently recognized as a specific entity characterized by acute deterioration of liver function in the context of compensated or even decompensated, but hitherto stable, cirrhosis. Worsening of liver function and subsequently of other end-organs occurs rapidly and follows a precipitating event that directly or indirectly affects liver function. Available data indicate that ICU mortality for ACLF ranges from $35 \%$ to $89 \%$ and in-hospital mortality ranges from $43 \%$ to $88 \%$. Patient outcome is not simply determined by the severity of liver disease. Indeed, the development and degree of end-stage organ failure represents the main determinant of outcome in ACLF patients. The pathophysiology of ACLF may be approached with the PIRO concept employed for sepsis (Predisposition, Infection/Inflammation, Response, Organ Failure). According to this approach, Predisposition is indicated by the severity of cirrhosis, Injury by nature/severity of the precipitating event(s), and the severity of inflammation and risk of infection express the patient's Response to injury. Finally, the extent of Organ failure is responsible for prognosis of ACLF patients. Current medical therapy involves management of the precipitating event, support end-organs and prevention/treatment of complications, until the eventual recovery of liver function. If medical treatment fails, transplantation is the only option in eligible patients. Characterization of the syndrome, definition of pathophysiological mechanisms, and improvement of patient management, currently call for ample efforts.
\end{abstract}

(c) 2013 Elsevier Ltd. All rights reserved.

\section{Introduction}

Liver failure can develop acutely in the absence of pre-existing liver disease (acute liver failure, ALF), in the presence of known or unknown chronic liver disease (acute on chronic liver failure, ACLF), or chronically, as decompensation of pre-existing end-stage liver disease (Table 1). In recent years, ACLF has been increasingly

Abbreviations: ALF, acute liver failure; ACLF, acute on chronic liver failure; ADMA, asymmetric dimethyl-L-arginine; APACHE, acute physiology, age and chronic health evaluation; APASL, Asia-Pacific association for the study of liver disease; ASA, American Society of Anesthesiologists; cGMP, cyclic guanosine monophosphate; eNOS, endothelial nitric oxide synthase; FABPS, fatty acid binding proteins; HBV, hepatitis B virus; HE, hepatic encephalopathy; HRS, hepatorenal syndrome; HVPG, hepatic vein pressure gradient; ICU, intensive care unit; IFN, interferon; IL, interleukin; iNOS, inducible nitric oxide synthase; INR, international normalized ratio; MARS, molecular adsorbent recirculating system; MELD, model of end stage liver disease; NAG, N-acetyl- $\beta$-(D)-glucosaminidase activity; NGAL, neutrophil gelatinase-associated lipocalin; NO, nitric oxide; PIRO, predisposition, infection/inflammation, response, organ failure; SIRS, systemic inflammatory response; SOFA, sequential organ failure assessment; TIPS, transjugular intrahepatic portosystemic shunt; TNF, tumour necrosis factor.

* Corresponding author. Dipartimento di Medicina Sperimentale e Clinica, Largo Brambilla, 3, 50134 Florence, Italy. Tel.: +39 0557945425; fax: +39 055417123.

E-mail address: fabio.marra@unifi.it (F. Marra). recognized as a specific entity characterized by acute deterioration of liver function in the context of compensated or even decompensated, but hitherto stable, cirrhosis. Worsening of liver function and subsequently of other organs occurs over a period of a few weeks and follows a precipitating event. This event may directly (e.g. drug- or alcohol-induced liver injury) or indirectly (e.g. sepsis, portal hypertension-related bleeding) affect liver function. The clinical features of ACLF imply rapid disease progression, the need for multiple organ support and poor short- and medium-term prognosis. ${ }^{1}$ However, a clear definition of ACLF is currently lacking, and some uncertainties emerge, as this term is being used by clinicians to define different conditions. Two consensus conferences elaborated a definition for this syndrome. The first definition of ACLF was provided by the Asia-Pacific Association for the Study of Liver Disease (APASL), as an 'acute hepatic insult manifesting as jaundice and coagulopathy, complicated within 4 weeks by ascites and/or encephalopathy in a patient with previously diagnosed or undiagnosed chronic liver disease'. ${ }^{2}$ Subsequently a second definition emerged from an EASL-AASLD single topic symposium, where ACLF was defined as an 'acute deterioration of pre-existing chronic liver disease, usually related to a precipitating event and associated with increased mortality at 3 months due to multi-system organ failure'. ${ }^{3}$ The second definition, if not stated 
Table 1

Comparison of end-stage liver disease and ACLF.

\begin{tabular}{ll}
\hline Present in both conditions & Unique to ACLF \\
\hline $\begin{array}{l}\text { Multi-organ failure } \\
\text { Deranged systemic } \\
\text { inflammatory response }\end{array}$ & $\begin{array}{l}\text { Potential reversibility } \\
\text { Precipitating event }\end{array}$ \\
& $\begin{array}{l}\text { High mortality compared } \\
\text { to cirrhotic patients with } \\
\text { similar MELD scores }\end{array}$ \\
\hline $\begin{array}{l}\text { Abbreviations: ACLF, acute on chronic liver failure; MELD, model of end stage liver } \\
\text { disease. }\end{array}$ &
\end{tabular}

otherwise, will be employed in the present review. Characterization of the syndrome, definition of pathophysiological mechanisms, and improvement of patient management, currently call for ample efforts. This review focuses on recently acquired concepts related to these various aspects. The pathophysiology of ACLF may be approached with the PIRO concept employed for sepsis (predisposition, infection/inflammation, response, organ failure). ${ }^{4}$ According to this approach, predisposition is indicated by the severity of cirrhosis, injury by nature/severity of the precipitating event(s), and the severity of inflammation and risk of infection expressed in the patient's response to injury. Finally, the extent of organ failure is responsible for the prognosis of ACLF patients. Categorization of patients with PIRO allows for a definition of therapeutic intervention and prognosis at different levels.

\section{Epidemiology, clinical scenario and prognosis $(\mathbf{P})$}

Limited data are available concerning ACLF epidemiology. Data obtained in a US patient sample, analysed in a EASL-AASLD single topic symposium on the management of critically ill cirrhotic patients in the intensive care unit (ICU), ${ }^{3}$ reported in-hospital mortality of $53 \%$ and mean hospitalization length of 14 days for ACLF. Prognostic factors predicting the outcome in patients with ACLF are currently under evaluation. In ACLF, two simultaneous insults are operating, acute and chronic. The degree of each injury is variable, with a prominent role for either type. Whether the prognosis of the patient depends on the degree of acute or chronic injury, or both, is still not well defined (Table 2). Accumulating evidence indicates that scoring systems simply addressing the severity of liver disease, such as the Child-Pugh ${ }^{5}$ or the Model of End Stage Liver Disease (MELD) scores, ${ }^{6}$ are not adequate in comparison to systems also evaluating extra-hepatic organ dysfunction such as the Sequential Organ Failure Assessment (SOFA) (Table 3) ${ }^{7}$ or the Acute Physiology, Age and Chronic Health Evaluation (APACHE) $)^{8}$ scores. $^{9}$ Available data indicate that ICU mortality for ACLF ranges from $35 \%$ to $89 \%$ and in-hospital mortality ranges from $43 \%$ to $88 \%{ }^{10-29}$ (for a comprehensive list of references see Ref. ${ }^{9}$ ). Although different criteria were employed in patient selection and follow-up, a careful evaluation of these data demonstrates that patient outcome is not merely determined by the severity of liver

\section{Table 2}

Grades of ACLF.

ACLF-1: Renal failure or a non-renal organ failure associated with creatinine 1.5

$-2 \mathrm{mg} / \mathrm{dL}$ and/or grade I-II encephalopathy;

ACLF-2: 2 organ failures

ACLF-3: 3 organ failures

ACLF-4: 4-6 organ failures

From R. Moreau et al., Diagnosis, prevalence, and prognosis of acute-on-chronic liver failure (ACLF): results of the EASL-chronic liver failure (CLIF) consortium CANONIC study. Abstract 1404, International Liver Congress 2012.

ACLF, acute on chronic liver failure.
Table 3

End organs failure according to SOFA score.

Liver failure will be defined by a SOFA sub-score of 4

Respiratory failure by a sub-SOFA score $\geq 3$ or requirement for mechanical ventilation

Haematologic failure by a sub-SOFA sub-score of 4 and/or INR $>2.5$

Cardiovascular failure by a sub-SOFA score $\geq 2$ (i.e. the use of vasopressors)

Neurologic failure by a sub-score $\geq 3$ (based upon the West Haven criteria) or requirement for endotracheal intubation to prevent aspiration pneumonia

Renal failure by a sub-SOFA score $\geq 2$ or requirement for renal-replacement therapy

Abbreviations: SOFA, sequential organ failure assessment; INR, international normalized ratio.

disease as expressed by conventional scoring systems (such as the Child-Pugh score), while the development and degree of end-stage organ failure represents the main determinant of outcome in ACLF patients.

\section{Pathophysiology}

\section{1. $\operatorname{Injury}(I)$}

The precipitating event may directly affect and worsen liver function such as in the case of drug-induced liver injury, alcoholic hepatitis, superimposed viral hepatitis, vascular diseases (mainly portal vein thrombosis or Budd-Chiari syndrome) and ischaemic hepatitis. Alternatively an extra-hepatic event may indirectly induce decompensation (portal hypertension-related bleeding, surgery, infection or trauma). Nonetheless, in a substantial proportion of patients no precipitating event can be identified. Survival of patients with bleeding related to portal hypertension can be improved by early administration of antibiotics or by insertion of a transjugular intrahepatic portosystemic shunt (TIPS), which is indicated in actively bleeding Child Pugh class B patients and in patients with advanced liver disease ${ }^{30,31}$ because cardiopulmonary events and the decline in hepatocellular function that follows failure to control bleeding and/or early rebleeding were prevented. Early antiviral therapy in patients acutely infected with HBV in the setting of pre-existing chronic liver disease prevents decompensation and improves survival. ${ }^{32}$

In patients undergoing surgery, the most relevant predictors of post-operative mortality were severity of liver disease as indicated by the MELD score, age, and the American Society of Anesthesiologists (ASA) score. ${ }^{33}$ It is conceivable that an altered patient response to direct or indirect injury implies an unregulated inflammatory response and immune dysfunction leading to increased susceptibility to infection and ultimately causing ACLF. This sequence of events defines a stereotyped common cascade unifying diverse precipitating injuries/events. ${ }^{34}$

\subsection{Inflammation and infection $(R)$}

The pivotal role of a systemic inflammatory response (SIRS) in ACLF emerges by its association with more severe encephalopathy, infections, renal failure and poor outcome. ${ }^{34-36}$ Elevated levels of multiple pro- and anti-inflammatory cytokines have been reported in patients with ACLF, including tumour necrosis factor (TNF)- $\alpha$, sTNF $\alpha$ R1, sTNF $\alpha$ R2, interleukin (IL)-2, IL-2R, IL-6, IL-8, IL-10, and interferon (IFN)- $\gamma{ }^{37,38}$ Although interference with these or other cytokine systems could be considered an appealing therapeutic strategy, only limited data are available. Moreover, the use of antiTNF- $\alpha$ in patients with alcoholic hepatitis has been associated with an increased risk of infection and greater mortality rates. ${ }^{39,40}$ Moreover, mortality associated with renal failure in cirrhotic 
patients is significantly higher in those with SIRS, ${ }^{41,42}$ emphasizing the possible pathogenic role of this condition.

Bacterial infections in cirrhosis are common, particularly in decompensated patients, and their occurrence increases mortality by two- to four-fold. ${ }^{43}$ About $40-50 \%$ of patients with ACLF present an infection at hospital admission and an additional $20-40 \%$ will develop nosocomial infections. The mortality rate for severe bacterial infection in cirrhotic patients is about $60-100 \%{ }^{43-47}$ Therefore, strict surveillance and repeated cultures are mandatory. Careful use of indwelling devices, including urinary catheters, and prompt prophylaxis or treatment of infections remain the cornerstones of patient management.

Several causes account for the increased susceptibility of these patients to bacterial infections. Liver dysfunction leads to several abnormalities of defence mechanisms, as both humoral and cellmediated immunity are depressed. Therefore SIRS may lead to immune dysregulation, predisposing to bacterial translocation and infection, that in turn will further aggravate a pro-inflammatory response. ${ }^{48}$ This vicious cycle ultimately results in sepsis, renal failure, bleeding or rebleeding, hepatic encephalopathy and death. ${ }^{49-53}$ Identification of biomarkers that predict susceptibility to infections could in the future allow for the stratification of patients in clinical categories with different risks, and therapy could be individualized. Along these lines, neutrophil dysfunction in ACLF seems reversible and probably due to circulating endotoxin. ${ }^{50}$ Interestingly preliminary data support a role for modulation of enteric microflora in the recovery of neutrophil phagocytic capacity ${ }^{52}$ (Fig. 1).

\subsection{Liver and other end-organs in $A C L F(O)$}

Although liver damage is the initiating event in ACLF, its occurrence triggers an involvement of other extrahepatic systems that eventually condition the prognosis of the patient (Fig. 2).

\subsection{Liver}

Jaundice is considered an essential sign for the diagnosis of ACLF. Various authors have used different cutoff levels of bilirubin, varying from a serum concentration of $6-20 \mathrm{mg} / \mathrm{dL}^{54-57}$ A cut-off

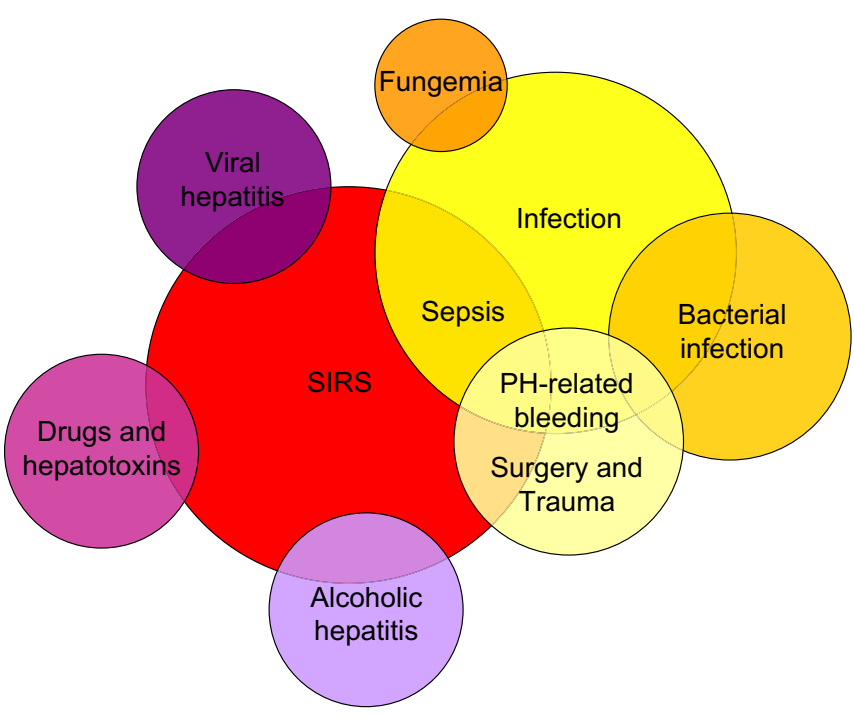

Fig. 1. Precipitating events in ACLF. Note that SIRS may even occur in the absence of injury. Infection and sepsis are mainly related to spontaneous bacterial peritonitis, pneumonia, urinary tract infection and skin infection. SIRS, systemic inflammatory response syndrome; PH, portal hypertension. Modified from Olson \& Kamath Curr Opin Crit care 2011,17:165.

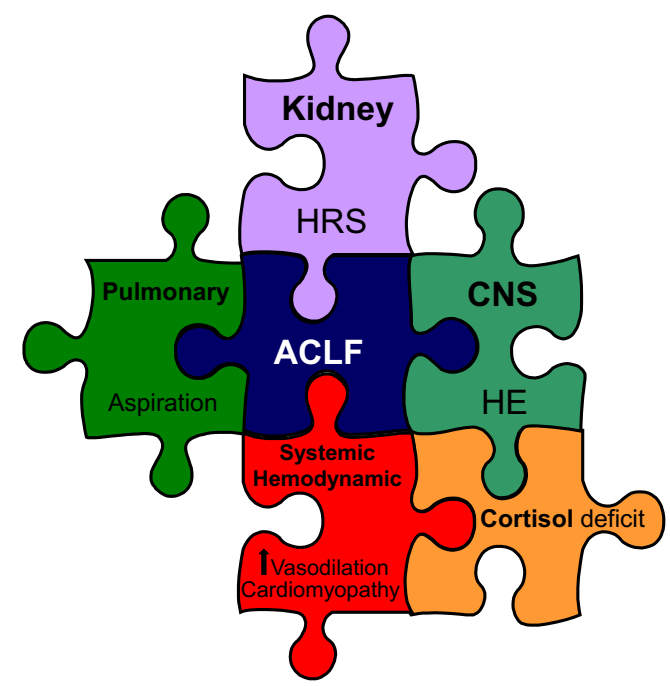

Fig. 2. The liver and other organs in acute on chronic liver failure (ACLF). CNS, central nervous system; HE, hepatic encephalopathy; HRS, hepatorenal syndrome.

level greater than $5 \mathrm{mg} / \mathrm{dL}$ of serum bilirubin was suggested in the APASL consensus recommendations. ${ }^{2}$ Coagulopathy was defined by APASL as a INR $>1.5$ or prothrombin activity less than $40 \%$.

An early biopsy may help in understanding the mechanisms involved and improve patient management (see liver histology in ACLF). Indeed, ACLF due to a non-specific injury such as variceal bleeding or bacterial infection is thought to cause different effects other than direct injury such as the ones caused by drugs, toxins or superimposed hepatitis. Recent evidence has highlighted the importance of bilirubinostasis and SIRS as early markers to allow identification of high-risk patients among those with acute deterioration of alcoholic cirrhosis and resultant ACLF. Moreover, bilirubin levels were strongly associated with an increased risk of subsequent infection. ${ }^{58,59}$

Liver inflammation markedly influences portal pressure, a major complication of cirrhosis and a critical determinant of prognosis, and superimposed alcoholic hepatitis in patients with alcoholic cirrhosis is a prototypical example of ACLF. In this context, experimental studies indicate that TNF- $\alpha$ could play an important role in the development of portal hypertension in alcoholic hepatitis. Indeed, anti TNF- $\alpha$ therapy has been reported to reduce portal pressure in patients with severe alcoholic hepatitis and cirrhosis. ${ }^{60}$ Several lines of evidence suggest that gut-derived endotoxaemia plays a pivotal role in the pathogenesis of portal hypertension, and therefore have a role in the pathogenesis of ACLF. ${ }^{61}$ In fact, modulation of gut flora by antibiotics administration ${ }^{62,63}$ or endotoxin neutralization with high density lipoproteins ${ }^{64}$ have been associated with the reduction of portal pressure. Moreover, reactive oxygen species also contribute to increase portal pressure, reducing the availability of intra-hepatic nitric oxide (NO), ${ }^{65}$ and resulting in increased intra-hepatic resistance to blood flow. Along these lines, hepatic eNOS activity has been shown to be reduced in the context of cirrhosis with superimposed inflammation. ${ }^{66,67}$ The liver also plays a prominent role in the metabolism of asymmetric dimethylL-arginine (ADMA), an endogenous inhibitor of nitric oxide synthase. Hepatocellular damage is a main determinant of elevated ADMA concentrations. ${ }^{68-72}$ Moreover, dysfunction of the cyclic GMP system has been indicated as an additional mechanism leading to reduced response to nitric oxide in cirrhotic livers. Interestingly, phosphodiesterase-5 inhibitors such as sildenafil, which increase cGMP, have been shown to have a beneficial effect on intra-hepatic resistance. ${ }^{73}$ 


\subsection{Kidney}

Acute kidney injury is a frequent and important feature of ACLF, as it is associated with poor prognosis. ${ }^{11-13,17,42,58,74,75}$ In general, changes in renal haemodynamics occur early in cirrhosis and culminate in a circulatory dysfunction that characterizes hepatorenal syndrome (HRS). HRS is characterized by a massive splanchnic vasodilatation, which reduces arterial blood pressure and leads to extreme renal vasoconstriction, impaired cardiac function and marked activation of the main vasoconstrictive systems $s^{76-78}$ (Table 4).

Hyperdynamic circulation is essential to maintain central blood volume and renal perfusion in cirrhosis. When cardiac output decreases, effective hypovolaemia is further enhanced, leading to additional recruitment of endogenous vasopressor systems followed by worsening of renal hypoperfusion and HRS. The mechanisms leading to decreasing cardiac output remain largely unknown, but SIRS has been suggested to be involved (see systemic haemodynamics and cardiac dysfunction). Gold standard treatments for HRS, which are directed to the restoration of arterial effective blood volume, are unsuccessful in $54 \%$ of patients, ${ }^{79}$ suggesting that in these patients different factors contribute to the development of renal dysfunction. Moreover, in $30-40 \%$ of cirrhotic patients with renal failure bacterial infection, e.g. spontaneous bacterial peritonitis, is the leading cause. ${ }^{77}$

The role of inflammation and/or oxidative stress in renal failure associated with ACLF is highlighted by the benefit of antiinflammatory agents such as albumin, pentoxifylline or $\mathrm{N}$-acetylcyteine, which decreased the risk of renal dysfunction in patients with alcoholic hepatitis. ${ }^{80,81}$ In ACLF, both prerenal and renal causes are involved in the pathogenesis of acute renal failure. Prerenal factors are generally associated with renal hypoperfusion, which may be associated with intravascular volume depletion (haemorrhage, renal and gastro-intestinal fluid loss). In other cases, a fullblown HRS express the type of kidney damage in the presence of marked deterioration of effective arterial blood volume. Most intrarenal causes are related to ischaemic acute tubular necrosis due to renal hypoperfusion.

Availability of urinary biomarkers in clinical practise may allow early diagnosis of renal impairment and the discrimination between functional and inflammatory causes. Markers of tubular injury such as kidney injury molecule-1 and alpha glutathione Stransferase or markers of inflammation such as NAG, NGAL, FABP, and IL- $18^{82}$ appear to be promising and will deserve further evaluation.

\subsection{Brain}

Metabolic encephalopathies refer to alterations of the brain's integrated activity in the absence of structural abnormalities. ${ }^{83}$ Clinical manifestations vary from mild executive dysfunction or agitated delirium to deep coma with decerebration. Encephalopathy

\begin{tabular}{l} 
Table 4 \\
Diagnostic criteria for the hepatorenal syndrome. \\
\hline - Cirrhosis with ascites \\
- Serum creatinine above $1.5 \mathrm{mg} \%(>1.33 \mathrm{mM})$ \\
- No improvement of serum creatinine (decrease to a level of $133 \mathrm{mmol} / \mathrm{L})$ after \\
at least 2 days with diuretic withdrawal and volume expansion with albumin. \\
The recommended dose of albumin is $1 \mathrm{~g} / \mathrm{Kg}$ of bodyweight per day up to \\
a maximum of $100 \mathrm{mg} /$ day \\
- Absence of shock \\
- No current or recent treatment with nephrotoxic drugs \\
- Absence of parenchymal kidney disease as indicated by proteinuria $>$ \\
$500 \mathrm{mg} /$ day, microhaematuria ( $>50$ red blood cells per high power field) \\
and/or abnormal renal ultrasonography
\end{tabular}

may represent a manifestation as well as a precipitating factor of ACLF. From a pathophysiological perspective, brain swelling is an important feature of ACLF. ${ }^{84-87}$ Ammonia is thought to play a key role in the development of hepatic encephalopathy (HE) but no direct relationship between the severity of hyperammonaemia and HE has been demonstrated. ${ }^{88}$ The current view is that a synergy between chronic increase in ammonia and inflammation related to an acute hepatic insult facilitate the development of brain oedema. The mechanism is likely related to generation of cytokines in the brain, increased iNOS expression, oxidative stress and formation of nitrated protein adducts. 87,89

The most common clinical entities observed in decompensated cirrhotic patients are hepatic and hyponatraemic encephalopathy and they may even co-exist. ${ }^{90}$ Mortality rate in ICU was $10 \%$ in patients with isolated encephalopathy and $80 \%$ in those with failure of other organs. ${ }^{91}$ In these patients airway protection represents a priority, and aspiration pneumonia and acute respiratory failure are major complications of encephalopathy.

\subsection{Systemic haemodynamics and cardiac dysfunction}

Portal hypertension associated with cirrhosis is initiated by an increase in intrahepatic vascular resistance, related both to fibrosis and to increased intrahepatic vascular tone. The resulting increase in splanchnic blood flow in turn gives rise to a hyperdynamic systemic state. The increased cardiac output observed in this situation is mainly due to a vasodilated splanchnic bed but paradoxically, the blood flow in other organs, such as kidneys or the brain is decreased. ${ }^{92}$

Circulatory failure in ACLF resembles severe sepsis and is typically characterized by an exacerbated hyperdynamic state with the inability to obtain adequate perfusion pressure despite volume expansion and large doses of inotropes, with subsequent appearance of lactic acidosis. ${ }^{93-97}$ Indeed, unlike decompensated cirrhosis, where cardiac output remains elevated, in ACLF a drop in cardiac output may be observed despite splanchnic vasodilation and both systolic and diastolic function may become affected. Cardiac dysfunction in ACLF, as well as in sepsis, is related to increased TNF- $\alpha$ and nitric oxide, and decreased cortisol levels, ${ }^{98}$ resulting in further vascular dilatation and decreased sensitivity to vasoconstrictors. Cortisol (see hepato-adrenal axis) is reduced in more than $50 \%$ of patients affected by chronic liver disease and concomitant sepsis, resulting in adrenal insufficiency. ${ }^{98-100}$ Cardiovascular collapse in ACLF is associated with increased mortality, especially in patients who present with other end-organ dysfunction and particularly renal failure. ${ }^{94}$ Therefore, is crucial to properly follow cardiac function to guide fluid replacement and inotropic support.

\subsection{Coagulation}

Regardless of abnormal routine coagulation tests, thrombin generation is normal in compensated or "stable decompensated" cirrhotic patients, due to a rebalancing of pro- and anti-coagulant factors that seldom leads to hypercoagulation, providing that platelet count is 'adequate', i.e. $>50,000 /$ uL. The prophylactic use of blood products, even in the context of variceal bleeding is no evidence-based and therefore empirical, and no effect of recombinant factor VIIa has been shown. ${ }^{101}$ Moreover, normalization of coagulation parameters is difficult to achieve and this practise could provoke transfusion-related acute lung injury, volume excess and other transfusion-associated reactions. However, endogenous low-molecular weight heparinoids are detected in cirrhotic patients with sepsis, and disappear with resolution of infection. ${ }^{46}$ Along these lines, administration of antibiotics in 
variceal bleeding is reported to reduce early rebleeding rate and mortality. ${ }^{102}$ Major coagulation abnormalities described in ACLF include increased fibrinolysis and defective platelet function. ${ }^{103}$ There is an unmet need for more comprehensive coagulation tests to guide correction of coagulation dysfunction on an individual basis.

\subsection{Hepato-adrenal axis}

Development of adrenal insufficiency worsens the prognosis of cirrhotic patients with severe sepsis. As stated above, this disorder has been reported in a considerable fraction (51-68\%) of patients with cirrhosis and severe sepsis, and particularly in those with haemodynamic instability and more advanced liver disease as expressed by MELD or Child-Pugh scores. Preliminary data indicate that administration of hydrocortisone in this setting may improve circulatory function. $^{98}$

\section{Portal pressure measurement in ACLF}

ACLF is an acute event on an underlying liver disease and hence portal pressure is thought to differ from that in patients with compensated and even decompensated cirrhosis. Kumar et al. ${ }^{104}$ demonstrated that patients with small varices and lower hepatic vein pressure gradient (HVPG) have a higher chance of recovery after the acute insult settles down. Conversely, patients with large varices or high HVPG have a poor prognosis following ACLF.

\section{Liver histology in ACLF}

Histologic data in ACLF are scarce, since it is not easy to obtain a liver specimen in these often very sick patients, and thus the need for a liver biopsy should be individualized. The transjugular approach is relatively safe in these patients and allows simultaneous evaluation of systemic haemodynamic and HVPG. Liver biopsy may provide information on the severity of the underlying liver disease, and may also be useful in identifying the etiology of the acute injury.

No histologic features are considered pathognomonic of ACLF. Single centre data ${ }^{105}$ discriminate two patterns with different prognosis: pattern I, characterized by hepatocyte ballooning, rosette formation, cellular cholestasis, variable interface activity and fibrosis; pattern II, with marked ductular proliferation, coarse, inspissated bile plugs, foci of confluent/bridging necrosis, eosinophilic degeneration of hepatocytes, higher stage of fibrosis and variable activity. Pattern II was associated with a much worse prognosis.

\section{Management of ACLF}

Current medical therapy involves management of the precipitating event, support end-organs and prevention/treatment of complications, until the eventual recovery of liver function. If medical treatment fails, transplantation is the only option in eligible patients. However, cadaveric organ shortage strongly limits this possibility, and alternative methods to support liver function are currently being investigated. Intensive care management of patients with ACLF is beyond the scope of this review. Otherwise, the main principles of multiple organ support have to be employed to allow treatment of acute injury and liver function recovery.

\subsection{Liver transplantation}

There is a paucity of data on liver transplantation in ACLF, even if this represents the only definitive therapy for patients who do not improve with supportive measures to multiple organs. Haemodynamic instability and the need for high-dose inotropes, raised intracranial pressure and reduction in cerebral perfusion pressure, and the presence of severe bacterial and/or fungal infections make patients often unsuitable to undergo transplantation. Therefore the timing is crucial as patients with ACLF may have a narrow window of opportunity. Following this line, living-donor transplantation may be an attractive option. Encouraging results are reported from South-East Asia in patients with ACLF due to re-activation of hepatitis $B$ virus infection. Indeed, an $80 \%$ survival at 5 years was reported in these patients. ${ }^{106}$ Bahirwani et al. ${ }^{107}$ also showed that ACLF was not an independent predictor of post-transplant mortality, arguing that this may be a good indication for transplantation. Nevertheless, in many centres there is no prioritized organ allocation for ACLF patients, due to scarcity of data and a supposedly higher short-term mortality. A better understanding of pathogenesis and natural history, and improvement in multiple organ support and in the prevention of complications will allow ACLF to be incorporated as a possible new indication for high urgency allocation.

\subsection{Liver support devices}

The role of hepatotoxins in the development of ACLF provides a rationale for the use of extracorporeal liver support systems. In principle, liver-assisting devices aim to provide detoxification functions to patients with ACLF, until liver function eventually recovers. Nonetheless, even if this approach is safe and well tolerated, devices failed to demonstrate any survival benefit in randomized studies. ${ }^{108-}$

${ }^{110}$ Two major types of liver support systems have been investigated, acellular devices such as albumin dialysis and plasma-exchange/ diafiltration (mainly MARS and Prometheus), and bio-artificial livers, which incorporate cells from human or animal sources, or immortalized cells. Preliminary data indicate a possible beneficial effect in ACLF induced by HBV reactivation. ${ }^{111}$ The best studied liver support devices are the Molecular Adsorbent Recirculating System (MARS) and Prometheus devices, which are based on the principle of albumin dialysis. ${ }^{112}$ Indeed, albumin exerts a number of functions besides its oncotic properties. These devices may remove inflammatory molecules, reduce NO and improve systemic and hepatic haemodynamics. ${ }^{109,113,114}$ Interestingly Prometheus showed a possible benefit in the sub-group of patients with a MELD score of $>30$ and in those with hepatorenal syndrome. ${ }^{109}$

\subsection{Cell-based therapies}

The therapeutic use of several types of cells has been hypothesized to improve ACLF. In a recent study, Garg et al. tested the possibility that mobilization of bone marrow-derived stem cells with granulocyte colony-stimulating factor could promote hepatic regeneration. ${ }^{115}$ Treatment with this cytokine resulted in a significantly higher survival and improvement of liver function parameters. These intriguing results await confirmation from different groups and different geographical areas.

\subsection{Use of antivirals in ACLF}

Spontaneous or iatrogenic (immunosuppression) flares of inflammation are frequently observed in chronic hepatitis B. Antiviral therapy should be immediately initiated in patients with ACLF related to re-activation of hepatitis $B$ or acute infection in the context of a different chronic liver disease. In general, drugs with high potency and a high genetic barrier such as entecavir or tenofovir should be preferred in view of the long term need for viral suppression. $^{2}$ 


\section{Conclusions}

ACLF is a devastating independent clinical syndrome with high mortality. ACLF follows a precipitating event and is defined as an acute and rapid worsening of liver function accompanied by subsequent multiple end-organ failure in a patient with previously compensated or reasonably compensated liver disease. The mortality of ACLF is known to be high in inpatients ( $>50 \%$ ), although no long-term data are available. In ACLF patients, a concept similar to the PIRO concept in sepsis (predisposition, infection/inflammation, response, organ failure) might be useful in describing the pathophysiology and clinical categories of this disorder. The pathophysiology of ACLF relates to an altered response to injury, resulting in an imbalanced inflammatory reaction and immune dysfunction leading to an increased susceptibility to infection. Management of the precipitating injury, multiple organ support and prevention and treatment of complications are the mainstay when dealing with ACLF patients. The liver transplant community will need to be more engaged to define which ACLF patients are better candidates for transplantation, and to define new allocation policies. Finally, a better definition of this clinical scenario is needed, possibly with the use of new biomarkers that allow development of new drugs and devices.

\section{Conflicts of interest}

None declared.

\section{References}

1. Jalan R, Williams R. Acute-on-chronic liver failure: pathophysiological basis of therapeutic options. Blood Purif 2002;20:252-61.

2. Sarin SK, Kumar A, Almeida JA, Chawla YK, Fan ST, Garg H, et al. Acute-onchronic liver failure: consensus recommendations of the Asian Pacific Association for the Study of the Liver (APASL). Hepatol Int 2009;3:269-82.

3. Olson JC, Wendon JA, Kramer DJ, Vicente A, Jalan R, Garcia-Tsao G, et al. Intensive care of the patient with cirrhosis. Hepatology 2011;54:1864-72.

4. Moreno RP, Metnitz B, Adler L, Hoechtl A, Bauer P, Metnitz PG, SAPS 3 Investigators. Sepsis mortality prediction based on predisposition, infection and response. Intensive Care Med 2008;34:496-504

5. Pugh RN, Murray-Lyon IM, Dawson JL, Pietroni MC, Williams R. Transection of the oesophagus for bleeding oesophageal varices. Br J Surg 1973;60:646-9.

6. Kamath PS, Wiesner RH, Malinchoc M, Kremers W, Therneau TM, Kosberg CL et al. A model to predict survival in patients with end-stage liver disease. Hepatology 2001;33:464-70.

7. Vincent JL, Moreno R, Takala J, Willatts S, De Mendonca A, Bruining $\mathrm{H}$, et al. The SOFA (Sepsis-related Organ Failure Assessment) score to describe organ dysfunction/failure. On behalf of the working group on sepsis-related problems of the European society of intensive care medicine. Intensive Care Med 1996;22:707-10.

8. Knaus WA, Draper EA, Wagner DP, Zimmerman JE. APACHE II: a severity of disease classification system. Crit Care Med 1985;13:818-29.

9. Jalan R, Gines P, Olson JC, Mookerjee RP, Moreau R, Garcia-Tsao G, et al. Acuteon chronic liver failure. J Hepatol 2012 [Epub ahead of print].

10. Zauner CA, Apsner RC, Kranz A, Kramer L, Madl C, Schneider B, et al. Outcome prediction for patients with cirrhosis of the liver in a medical ICU: a comparison of the APACHE scores and liver-specific scoring systems. Intensive Care Med 1996;22:559-63.

11. Zimmerman JE, Wagner DP, Seneff MG, Becker RB, Sun X, Knaus WA. Intensive care unit admissions with cirrhosis: risk-stratifying patient groups and predicting individual survival. Hepatology 1996;23:1393-401.

12. Aggarwal A, Ong JP, Younossi ZM, Nelson DR, Hoffman-Hogg L, Arroliga AC. Predictors of mortality and resource utilization in cirrhotic patients admitted to the medical ICU. Chest 2001;119:1489-97.

13. Wehler M, Kokoska J, Reulbach U, Hahn EG, Strauss R. Short-term prognosis in critically ill patients with cirrhosis assessed by prognostic scoring systems Hepatology 2001;34:255-61.

14. Tsai MH, Peng YS, Lien JM, Weng HH, Ho YP, Yang C, et al. Multiple organ system failure in critically ill cirrhotic patients. A comparison of two multiple organ dysfunction/failure scoring systems. Digestion 2004;69:190-200.

15. Chen YC, Tsai MH, Hsu CW, Ho YP, Lien JM, Chang MY, et al. Role of serum creatinine and prognostic scoring systems in assessing hospital mortality in critically ill cirrhotic patients with upper gastrointestinal bleeding. J Nephrol 2003;16:558-65.
16. Ho YP, Chen YC, Yang C, Lien JM, Chu YY, Fang JT, et al. Outcome prediction for critically ill cirrhotic patients: a comparison of APACHE II and Child-Pugh scoring systems. J Intensive Care Med 2004;19:105-10.

17. Cholongitas E, Senzolo M, Patch D, Kwong K, Nikolopoulou V, Leandro G, et al. Risk factors, sequential organ failure assessment and model for end-stage liver disease scores for predicting short term mortality in cirrhotic patients admitted to intensive care unit. Aliment Pharmacol Ther 2006;23:883-93.

18. Afessa B, Kubilis PS. Upper gastrointestinal bleeding in patients with hepatic cirrhosis: clinical course and mortality prediction. Am J Gastroenterol 2000;95: 484-9.

19. Rabe C, Schmitz V, Paashaus M, Musch A, Zickermann H, Dumoulin FL, et al. Does intubation really equal death in cirrhotic patients? Factors influencing outcome in patients with liver cirrhosis requiring mechanical ventilation. Intensive Care Med 2004;30:1564-71.

20. du Cheyron D, Bouchet B, Parienti JJ, Ramakers M, Charbonneau P. The attributable mortality of acute renal failure in critically ill patients with liver cirrhosis. Intensive Care Med 2005;31:1693-9.

21. Knaus WA, Wagner DP, Draper EA, Zimmerman JE, Bergner M, Bastos PG, et al. The APACHE III prognostic system. Risk prediction of hospital mortality for critically ill hospitalized adults. Chest 1991;100:1619-36.

22. Arabi Y, Ahmed QA, Haddad S, Aljumah A, Al-Shimemeri A. Outcome predictors of cirrhosis patients admitted to the intensive care unit. Eur J Gastroenterol Hepatol 2004;16:333-9.

23. Jenq CC, Tsai MH, Tian YC, Lin CY, Yang C, Liu NJ, et al. RIFLE classification can predict short-term prognosis in critically ill cirrhotic patients. Intensive Care Med 2007;33:1921-30.

24. Juneja D, Gopal PB, Kapoor D, Raya R, Sathyanarayanan M, Malhotra P. Outcome of patients with liver cirrhosis admitted to a specialty liver intensive care unit in India. J Crit Care 2009;24:387-93.

25. Thomson SJ, Moran C, Cowan ML, Musa S, Beale R, Treacher D, et al. Outcomes of critically ill patients with cirrhosis admitted to intensive care: an important perspective from the non-transplant setting. Aliment Pharmacol Ther 2010;32: 233-43.

26. Juneja D, Gopal PB, Kapoor D, Raya R, Sathyanarayanan M. Profiles and outcome of patients with liver cirrhosis requiring mechanical ventilation. $J$ Intensive Care Med 2012;27:373-8.

27. Levesque E, Hoti E, Azoulay D, Ichaï P, Habouchi H, Castaing D, et al. Prospective evaluation of the prognostic scores for cirrhotic patients admitted to an intensive care unit. J Hepatol 2012;56:95-102.

28. Cavallazzi R, Awe OO, Vasu TS, Hirani A, Vaid U, Leiby BE, et al. Model for endstage liver disease score for predicting outcome in critically ill medical patients with liver cirrhosis. J Crit Care 2012;27:424.e1-6.

29. Shawcross DL, Austin MJ, Abeles RD, McPhail MJ, Yeoman AD, Taylor NJ, et al. The impact of organ dysfunction in cirrhosis: survival at a cost? J Hepatol 2012;56:1054-62.

30. Bernard B, Grange JD, Khac EN, Amiot X, Opolon P, Poynard T. Antibiotic prophylaxis for the prevention of bacterial infections in cirrhotic patients with gastrointestinal bleeding: a meta-analysis. Hepatology 1999;29:1655-61.

31. García-Pagán JC, Caca K, Bureau C, Laleman W, Appenrodt B, Luca A, et al, Early TIPS (Transjugular Intrahepatic Portosystemic Shunt) Cooperative Study Group. Early use of TIPS in patients with cirrhosis and variceal bleeding. N Engl J Med 2010;362:2370-9.

32. Garg H, Sarin SK, Kumar M, Garg V, Sharma BC, Kumar A. Tenofovir improves the outcome in patients with spontaneous reactivation of hepatitis B presenting as acute-on-chronic liver failure. Hepatology 2011;53:774-80.

33. Plataki M, Hubmayr RD. The physical basis of ventilator-induced lung injury. Expert Rev Respir Med 2010;4:373-85.

34. Jalan R, Olde Damink SW, Hayes PC, Deutz NE, Lee A. Pathogenesis of intracranial hypertension in acute liver failure: inflammation, ammonia and cerebral blood flow. J Hepatol 2004;41:613-20.

35. Rolando N, Wade J, Davalos M, Wendon J, Philpott-Howard J, Williams R. The systemic inflammatory response syndrome in acute liver failure. Hepatology 2000;32:734-9.

36. Vaquero J, Polson J, Chung C, Helenowski I, Schiodt FV, Reisch J, et al. Infection and the progression of hepatic encephalopathy in acute liver failure. Gastroenterology 2003;125:755-64.

37. Gustot T. Multiple organ failure in sepsis: prognosis and role of systemic inflammatory response. Curr Opin Crit Care 2011;17:153-9.

38. Sen S, Davies NA, Mookerjee RP, Cheshire LM, Hodges SJ, Williams R, et al. Pathophysiological effects of albumin dialysis in acute-on-chronic liver failure: a randomized controlled study. Liver Transpl 2004;10:1109-19.

39. Naveau S, Chollet-Martin S, Dharancy S, Mathurin P, Jouet P, Piquet MA et al, Foie-alcool group of the association Française pour l'Etude du Foie. A double blind randomized controlled trial of infliximab associated with prednisolone in acute alcoholic hepatitis. Hepatology 2004;39:1390-7.

40. Boetticher NC, Peine CJ, Kwo P, Abrams GA, Patel T, Aqel B, et al. A randomized, double-blinded, placebo-controlled multicenter trial of etanercept in the treatment of alcoholic hepatitis. Gastroenterology 2008;135:1953-60.

41. Cazzaniga M, Dionigi E, Gobbo G, Fioretti A, Monti V, Salerno F. The systemic inflammatory response syndrome in cirrhotic patients: relationship with their in-hospital outcome. J Hepatol 2009;51:475-82.

42. Thabut D, Massard J, Gangloff A, Carbonell N, Francoz C, Nguyen-Khac E, et al. Model for end-stage liver disease score and systemic inflammatory response are major prognostic factors in patients with cirrhosis and acute functional renal failure. Hepatology 2007;46:1872-82. 
43. Arvaniti V, D’Amico G, Fede G, Manousou P, Tsochatzis E, Pleguezuelo M, et al. Infections in patients with cirrhosis increases mortality four-fold and should be used in determining prognosis. Gastroenterology 2010;139:1246-56.

44. Linderoth G, Jepsen P, Schønheyder HC, Johnsen SP, Sørensen HT. Short-term prognosis of community-acquired bacteremia in patients with liver cirrhosis or alcoholism: a population-based cohort study. Alcohol Clin Exp Res 2006;30: 636-41.

45. Borzio M, Salerno F, Piantoni L, Cazzaniga M, Angeli P, Bissoli F, et al. Bacterial infection in patients with advanced cirrhosis: a multicentre prospective study. Dig Liver Dis 2001;33:41-8.

46. Montalto P, Vlachogiannakos J, Cox DJ, Pastacaldi S, Patch D, Burroughs AK. Bacterial infection in cirrhosis impairs coagulation by a heparin effect: a prospective study. J Hepatol 2002;37:463-70.

47. Gustot T, Durand F, Lebrec D, Vincent JL, Moreau R. Severe sepsis in cirrhosis. Hepatology 2009;50:2022-33.

48. Malik R, Mookerjee RP, Jalan R. Infection and inflammation in liver failure: two sides of the same coin. J Hepatol 2009;51:426-9.

49. Wasmuth HE, Kunz D, Yagmur E, Timmer-Stranghöner A, Vidacek D, Siewert E, et al. Patients with acute on chronic liver failure display "sepsislike" immune paralysis. J Hepatol 2005;42:195-201.

50. Mookerjee RP, Stadlbauer V, Lidder S, Wright GA, Hodges SJ, Davies NA, et al. Neutrophil dysfunction in alcoholic hepatitis superimposed on cirrhosis is reversible and predicts outcome. Hepatology 2007;46:831-40.

51. Berry PA, Antoniades CG, Carey I, McPhail MJ, Hussain MJ, Davies ET, et al. Severity of the compensatory anti-inflammatory response determined by monocyte HLA-DR expression may assist outcome prediction in cirrhosis. Intensive Care Med 2011:37:453-60.

52. Stadlbauer V, Mookerjee RP, Hodges S, Wright GA, Davies NA, Jalan R. Effect of probiotic treatment on deranged neutrophil function and cytokine responses in patients with compensated alcoholic cirrhosis. J Hepatol 2008;48:945-51.

53. Ariza J, Gudiol F, Dolz C, Xiol J, Liñares J, Bosch J, et al. Evaluation of aztreonam in the treatment of spontaneous bacterial peritonitis in patients with cirrhosis. Hepatology 1986;6:906-10.

54. Wagholikar GD, Lee KH, Pandey D, Leong SO, Singh R, Tan KC. Pre-transplant optimization by molecular adsorbent recirculating system in patients with severely decompensated chronic liver disease. Indian J Gastroenterol 2007;26: 110-2.

55. Wai CT, Lim SG, Aung MO, Lee YM, Sutedja DS, Dan YY, et al. MARS: a futile tool in centres without active liver transplant support. Liver Int 2007;27:69-75.

56. Du WB, Li LJ, Huang JR, Yang Q, Liu XL, Li J, et al. Effects of artificial liver support system on patients with acute or chronic liver failure. Transplant Proc 2005;37:4359-64.

57. Stadlbauer V, Krisper P, Aigner R, Haditsch B, Jung A, Lackner C, et al. Effect of extracorporeal liver support by MARS and Prometheus on serum cytokines in acute-on-chronic liver failure. Crit Care 2006;10:R169.

58. Katoonizadeh A, Laleman W, Verslype C, Wilmer A, Maleux G, Roskams T, et al. Early features of acute-on-chronic alcoholic liver failure: a prospective cohort study. Gut 2010;59:1561-9.

59. Jalan R, Mookerjee RP. Acute-on-chronic liver failure: an early biopsy is essential? Gut 2010:59:1455-6.

60. Mookerjee RP, Sen S, Davies NA, Hodges SJ, Williams R, Jalan R. Tumour necrosis factor $\alpha$ is an important mediator of portal and systemic haemodynamic derangements in alcoholic hepatitis. Gut 2003;52:1182-7.

61. Benten D, Wiest R. Gut microbiome and intestinal barrier failure - the "Achilles heel" in hepatology? J Hepatol 2012;56:1221-3.

62. Vlachogiannakos J, Saveriadis AS, Viazis N, Theodoropoulos I, Foudoulis K, Manolakopoulos S, et al. Intestinal decontamination improves liver haemodynamics in patients with alcohol-related decompensated cirrhosis. Aliment Pharmacol Ther 2009;29:992-9.

63. Rasaratnam B, Kaye D, Jennings G, Dudley F, Chin-Dusting J. The effect of selective intestinal decontamination on the hyperdynamic circulatory state in cirrhosis. A randomized trial. Ann Intern Med 2003;139:186-93.

64. Thabut D, Tazi KA, Bonnefont-Rousselot D, Aller M, Farges O, Guimont MC, et al. High-density lipoprotein administration attenuates liver proinflammatory response, restores liver endothelial nitric oxide synthase activity, and lowers portal pressure in cirrhotic rats. Hepatology 2007;46:1893-906.

65. Laviña B, Gracia-Sancho J, Rodríguez-Vilarrupla A, Chu Y, Heistad DD, Bosch J, et al. Superoxide dismutase gene transfer reduces portal pressure in $\mathrm{CCl}_{4}$ cirrhotic rats with portal hypertension. Gut 2009;58:118-25.

66. Mookerjee RP, Wiesenthal A, Icking A, Hodges SJ, Davies NA, Schilling K, et al. Increased gene and protein expression of the novel eNOS regulatory protein NOSTRIN and a variant in alcoholic hepatitis. Gastroenterology 2007;132: 2533-41.

67. Shah V, Haddad FG, Garcia-Cardena G, Frangos JA, Mennone A, Groszmann RJ, et al. Liver sinusoidal endothelial cells are responsible for nitric oxide modulation of resistance in the hepatic sinusoids. J Clin Invest 1997;100: 2923-30.

68. Mookerjee RP, Dalton RN, Davies NA, Hodges SJ, Turner C, Williams R, et al Inflammation is an important determinant of levels of the endogenous nitric oxide synthase inhibitor asymmetric dimethylarginine (ADMA) in acute liver failure. Liver Transpl 2007;13:400-5.

69. Lluch P, Mauricio MD, Vila JM, Segarra G, Medina P, Del Olmo JA, et al. Accumulation of symmetric dimethylarginine in hepatorenal syndrome. Exp Biol Med (Maywood) 2006;231:70-5.
70. Vizzutti F, Romanelli RG, Arena U, Rega L, Brogi M, Calabresi C, et al. ADMA correlates with portal pressure in patients with compensated cirrhosis. Eur J Clin Invest 2007;37:509-15.

71. Lluch P, Torondel B, Medina P, Segarra G, Del Olmo JA, Serra MA, et al. Plasma concentrations of nitric oxide and asymmetric dimethylarginine in human alcoholic cirrhosis. J Hepatol 2004;41:55-9.

72. Mookerjee RP, Malaki M, Davies NA, Hodges SJ, Dalton RN, Turner C, et al. Increasing dimethylarginine levels are associated with adverse clinical outcome in severe alcoholic hepatitis. Hepatology 2007;45:62-71.

73. Lee KC, Yang YY, Wang YW, Hou MC, Lee FY, Lin HC, et al. Acute administration of sildenafil enhances hepatic cyclic guanosine monophosphate production and reduces hepatic sinusoid resistance in cirrhotic patients. Hepatol Res 2008;38:1186-93.

74. Duseja A, Chawla YK, Dhiman RK, Kumar A, Choudhary N, Taneja S. Nonhepatic insults are common precipitants in patients with acute on chronic liver failure (ACLF). Dig Dis Sci 2010;55:3188-92.

75. Karvellas CJ, Pink F, McPhail M, Austin M, Auzinger G, Bernal W, et al. Bacteremia, acute physiology and chronic health evaluation II and modified end stage end liver disease are independent predictors of mortality in critically ill non-transplanted patients with acute on chronic liver failure. Crit Care Med 2010;38:121-6.

76. Gines P, Schrier RW. Renal failure in cirrhosis. N Engl J Med 2009;361 1279-90.

77. Martín-Llahí M, Guevara M, Torre A, Fagundes C, Restuccia T, Gilabert R, et al Prognostic importance of the cause of renal failure in patients with cirrhosis Gastroenterology 2011;140:488-96.

78. Stadlbauer V, Wright G, Banaji M, Mukhopadhyay A, Mookerjee R, Moore K, et al. Relationship between activation of the sympathetic nervous system and renal blood flow autoregulation in cirrhosis. Gastroenterology 2008;134 111-9.

79. Nazar A, Pereira GH, Guevara M, Martín-Llahi M, Pepin MN, Marinelli M et al. Predictors of response to therapy with terlipressin and albumin in patients with cirrhosis and type 1 hepatorenal syndrome. Hepatology 2010;51:219-26.

80. Holt S, Goodier D, Marley R, Patch D, Burroughs A, Fernando B, et al Improvement in renal function in hepatorenal syndrome with $\mathrm{N}$-acetylcysteine. Lancet 1999;353:294-5.

81. Akriviadis E, Bolta R, Briggs W, Han S, Reynolds T, Shakil O. Pentoxifylline improves short-term survival in severe alcoholic hepatitis: a double-blind placebo-controlled trial. Gastroenterology 2000;119:1637-48.

82. Cárdenas A, Ginès P. Acute-on-chronic liver failure: the kidneys. Curr Opin Crit Care 2011;17:184-9.

83. Bleck TP, Smith MC, Pierre-Louis SJ, Jares JJ, Murray J, Hansen CA. Neurologic complications of critical medical illnesses. Crit Care Med 1993;21:98-103.

84. Crippin JS, Gross Jr JB, Lindor KD. Increased intracranial pressure and hepatic encephalopathy in chronic liver disease. Am J Gastroenterol 1992;87:879-82.

85. Jalan R, Dabos K, Redhead DN, Lee A, Hayes PC. Elevation of intracrania pressure following transjugular intrahepatic portosystemic stent-shunt for variceal haemorrhage. J Hepatol 1997;27:928-33.

86. Donovan JP, Schafer DF, Shaw Jr BW, Sorrell MF. Cerebral edema and increased intracranial pressure in chronic liver disease. Lancet 1998:351: 719-21.

87. Wright G, Davies NA, Shawcross DL, Hodges SJ, Zwingmann C, Brooks HF, et al. Endotoxemia produces coma and brain swelling in bile duct ligated rats. Hepatology 2007;45:1517-26.

88. Shawcross DL, Sharifi Y, Canavan JB, Yeoman AD, Abeles RD, Taylor NJ, et al. Infection and systemic inflammation, not ammonia, are associated with grade $3 / 4$ hepatic encephalopathy, but not mortality in cirrhosis. J Hepatol 2011;54 640-9.

89. Pedersen HR, Ring-Larsen H, Olsen NV, Larsen FS. Hyperammonemia act synergistically with lipopolysaccharide in inducing changes in cerebral hemodynamics in rats anaesthetised with pentobarbital. $J$ Hepatol 2007;47: 245-52.

90. Cordoba J, Garcia-Martinez R, Simon-Talero M. Hyponatremic and hepatic encephalopathies: similarities, differences and coexistence. Metab Brain Dis 2010;25:73-80.

91. Fichet J, Mercier E, Genee O, Garot D, Legras A, Dequin PF, et al. Prognosis and 1-year mortality of intensive care unit patients with severe hepatic encephalopathy. I Crit Care 2009;24:364-70.

92. Helmy A, Jalan R, Newby DE, Hayes PC, Webb DJ. Role of angiotensin II in regulation of basal and sympathetically stimulated vascular tone in early and advanced cirrhosis. Gastroenterology 2000;118:565-72.

93. Liu H, Lee SS. Acute-on-chronic liver failure: the heart and systemic hemodynamics. Curr Opin Crit Care 2011;17:190-4.

94. Ruiz-del-Arbol L, Monescillo A, Arocena C, Valer P, Ginès P, Moreira V, et al. Circulatory function and hepatorenal syndrome in cirrhosis. Hepatology 2005;42:439-47.

95. Laleman W. Hemodynamic effects of albumin dialysis in patients with liver failure: for better or for worse? Ther Apher Dial 2009;13:384-92.

96. Schmidt LE, Sorensen VR, Svendsen LB, Hansen BA, Larsen FS. Hemodynamic changes during a single treatment with the molecular adsorbents recirculating system in patients with acute-on-chronic liver failure. Liver Transpl 2001;7:1034-9.

97. Laleman W, Wilmer A, Evenepoel P, Elst IV, Zeegers M, Zaman Z, et al. Effect of the molecular adsorbent recirculating system and prometheus devices on 
systemic haemodynamics and vasoactive agents in patients with acute-onchronic alcoholic liver failure. Crit Care 2006;10:R108.

98. Fernández J, Escorsell A, Zabalza M, Felipe V, Navasa M, Mas A, et al. Adrenal insufficiency in patients with cirrhosis and septic shock: effect of treatment with hydrocortisone on survival. Hepatology 2006;44:1288-95.

99. Marik P, Gayowski T, Starzi T, Hepatic Cortisol Research and Adrenal Pathophysiology Study Group. The hepatoadrenal syndrome: a common yet unrecognized clinical condition. Crit Care Med 2003;33:1254-9.

100. Tsai MH, Peng YS, Chen YC, Liu NJ, Ho YP, Fang JT, et al. Adrenal insufficiency in patients with cirrhosis, severe sepsis and septic shock. Hepatology 2006;43: $673-81$.

101. Bosch J, Thabut D, Albillos A, Carbonell N, Spicak J, Massard J, et al, International Study Group on rFVIIa in UGI Hemorrhage. Recombinant factor VIIa for variceal bleeding in patients with advanced cirrhosis: a randomized, controlled trial. Hepatology 2008;47:1604-14.

102. Jun $\mathrm{CH}$, Park $\mathrm{CH}$, Lee WS, Joo YE, Kim HS, Choi SK, et al. Antibiotic prophylaxis using third generation cephalosporins can reduce the risk of early rebleeding in the first acute gastroesophageal variceal hemorrhage: a prospective randomized study. J Korean Med Sci 2006;21:883-90.

103. Lisman T, Porte RJ. Platelet function in patients with cirrhosis. J Hepato 2012;56:993-4.

104. Kumar A, Das K, Sharma P, Mehta V, Sharma BC, Sarin SK. Hemodynamic studies in acute-on-chronic liver failure. Dig Dis Sci 2009;54:pp.869-878.

105. Sakhuja P, Rastogi A, Gondal R, Garg H, Sarin SK. Acute on chronic liver failure analysis of two distinct liver histological patterns [abstract]. J Hepatol 2008;48:S95.

106. Chen Z, Wen T, Zeng Y, Wang L, Lu JJ, Gong S, et al. A single institution experience with living donor liver transplantation for acute-on-chronic hepatitis B liver failure. Hepatogastroenterology 2011;58:1267-73.
107. Bahirwani R, Shaked O, Bewtra M, Forde K, Reddy KR. Acute-on-chronic liver failure before liver transplantation: impact on post-transplant outcomes. Transplantation 2011;92:952-7.

108. Banares R, Nevens F, Larsen FS, Jalan R, Albillos A, Dollinger M, et al. Extracorporeal albumin dialysis with the molecular adsorbent recirculating system in acute-on-chronic liver failure: The RELIEF trial. Hepatology 2012 Dec 5. http://dx.doi.org/10.1002/hep.26185. [Epub ahead of print].

109. Kribben A, Gerken G, Haag S, Herget-Rosenthal S, Treichel U, Betz C, et al. Effects of fractionated plasma separation and adsorption on survival in patients with acute-on-chronic liver failure. Gastroenterology 2012;142:782-9.

110. Stadlbauer V, Davies NA, Sen S, Jalan R. Artificial liver support systems in the management of complications of cirrhosis. Semin Liver Dis 2008;28:96-109.

111. Zhong-Ping Duan JZ, Xin S, Ju Chen M, He D, Brotherthon J, Maxwell K, et al. Interim results of randomized controlled trial of ELAD in acute on chronic liver disease. Hepatology 2007;46:274A.

112. Stange J, Mitzner S, Ramlow W, Gliesche T, Hickstein H, Schmidt R. A new procedure for the removal of protein bound drugs and toxins. ASAIO J 1993;39(3):M621-5.

113. Jalan R, Schnurr K, Mookerjee RP, Sen S, Cheshire L, Hodges S, et al. Alterations in the functional capacity of albumin in patients with decompensated cirrhosis is associated with increased mortality. Hepatology 2009;50:555-64.

114. Wright G, Vairappan B, Stadlbauer V, Mookerjee RP, Davies NA, Jalan R. Reduction in hyperammonaemia by ornithine phenylacetate prevents lipopolysaccharide-induced brain edema and coma in cirrhotic rats. Liver Int 2012;32:410-9.

115. Garg V, Garg H, Khan A, Trehanpati N, Kumar A, Sharma BC, et al. Granulocyte colony-stimulating factor mobilizes $\mathrm{CD} 34(+)$ cells and improves survival of patients with acute-on-chronic liver failure. Gastroenterology 2012;142:505-12. 